\title{
RESEARCH ARTICLE \\ AN ANALYSIS OF SOLID WASTE MANAGEMENT PRACTICES IN LAMJUNG DISTRICT COMMUNITY HOSPITAL, NEPAL
}

\author{
Mahendra Aryal ${ }^{1,2}$, Sanju Adhikary ${ }^{3}$, Vinayak Aryal ${ }^{4}$, Rameshwor Adhikari1,5 \\ ${ }^{1}$ Research Center for Applied Science and Technology, Tribhuvan University, Kathmandu, Nepal. \\ ${ }^{2}$ Department of Chemistry, Tri-Chandra Multiple Campus, Tribhuvan University, Kathmandu, Nepal. \\ ${ }^{3}$ Department of Economics, School of Law, Kathmandu University, Dhulikhel, Nepal. \\ ${ }^{4}$ Lamjung District Community Hospital, Lamjung, Nepal. \\ ${ }^{5}$ Central Department of Chemistry, Tribhuvan University, Kathmandu, Nepal \\ *Corresponding author Email: mahendraaryalnp@yahoo.com
}

This is an open access article distributed under the Creative Commons Attribution License, which permits unrestricted use, distribution, and reproduction in any medium, provided the original work is properly cited.

\section{ARTICLE DETAILS}

\section{Article History:}

Received 19 August 2019 Accepted 23 September 2019 Available online 24 December 2019

\section{ABSTRACT}

This study assessed the process of managing the health care wastes and their disposal in one of the major hospital in Lamjung district, Nepal. It was found that the hospital does not quantify solid wastes and segregation of the different types of wastes is not so well practiced. Average awareness of the magnitude of hospital waste management of hospital staffs and patients ages ranging from 15 to 85 was found at $67.857 \%$ and $49 \%$ respectively. The findings in this paper indicated that the waste generation rate is around $0.860 \mathrm{~kg} / \mathrm{inpatient} / \mathrm{day}, 0.053$ $\mathrm{kg} /$ outpatient/day. Total waste generation by hospital was estimated at $141.765 \mathrm{~kg} / \mathrm{day}$, in which $91.939 \%$ of nonhazardous and $8.060 \%$ of hazardous respectively. The study showed that almost all infectious wastes are disposed by incineration process. It was also found that the hospital has been still using mercury thermometer. Total cost of hospital waste management was an amount of \$US 26538.717 in 2018 AD including remuneration of waste management workers, whereas income from selling off recyclable waste is negligible comparison to the total cost. It can be recommended that the government and relevant agents should be at alert to their responsibilities of regulating the waste management practices in big hospitals.

\section{KEYWORDS}

Waste, Segregation, Generation rate, Waste management, Economic analysis.

\section{INTRODUCTION}

In recent years, amount of waste generated by society has increased drastically following the trends of population raise [1,2]. The production of waste materials is referred as the waste stream and includes the entire variety of refused waste from domestic, industrial, construction and commercial processes $[3,4]$. Health-care waste represents to all biological and non-biological waste that is discarded and not intended for further use. Health-care waste generation depends on various factors such as established waste management methods, type of health-care establishment, hospital specializations, proportion of reusable items employed in health care and proportion of patients treated on a day-care basis $[1,5,6]$. The composition of wastes included syringes, anatomical waste, cultures, medicines, chemical wastes, rubber, gloves, tubing, swabs, gauze, pads, glasses, surgical instruments, bandage, drop-bags, cardboard, paper, wood and plastics etc. [7,8]. The biomedical wastes can potentially transmit diseases and pose an additional risk to the staff of the healthcare facilities, patients and the community as a whole, when the wastes are not managed properly using scientific and discriminate methods [8-13].

Health-care waste may cause serious health risks and deteriorate the quality of life of the community through transmission of diseases and injury, if not disposed off correctly [14]. The inappropriate treatment or disposal of that waste is one of the major reasons of environmental pollution [15]. Currently, several methods such as incineration, autoclaving, microwaving, land filling and plasma pyrolysis have been using to treat healthcare wastes [14]. It is essential to comprehend the waste category and volume before selecting the proper treatment technology, since various types of wastes have to be managed differently $[14,16,17]$. Therefore, healthcare facilities must employ efficient and proper treatment with disposal technologies $[1,16,17]$. Hence, many potential evaluation factors including economical, technical, environmental and social must be considered to determine an appropriate waste treatment alternative for safe healthcare management $[16,17]$.

The developed countries have managed proper and sufficient infrastructure for health-care waste disposal $[15,18]$. A well-trained team is responsible for handling various operational procedures related to waste disposal like segregation, internal transportation and final disposal $[3,8,15,18,19]$. In low-income and middle countries, health-care waste generation is usually lower than in high-income countries, and there is lack of public awareness followed by improper health policy and law, and thus hospital waste is generally mixed with municipal waste [5,8]. Until recently, in Nepal, there is no system for proper health-care waste management and lack to protect environmental health hazards. It is generally disposed off in the same way as ordinary domestic wastes [19].

Improper health-care waste management is alarming in Nepal and it poses a serious threat to public health [8]. There is lack of awareness regarding segregation, collection, storage, transportation and disposal methods [19]. Most hazardous and toxic health care wastes are mixed with municipal wastes and placed on land sites with few safeguards to protect those living nearby and water sources from contamination $[14,3,8]$. Medical waste must be collected and treated separately from municipal waste, but in 
many parts of Nepal, it tends to be collected along with the rest of the waste stream $[8,19]$. In Nepal, many hospitals do not own the facility to dispose off medical wastes, which are hazardous to public health and environment [8]. Despite the government regulation, requiring every hospital to properly dispose off waste, authorities have often failed to enforce it [19].

The main purpose of this research are; (a) to evaluate the practices in terms of storage, collection, transportation and disposal off health-care waste, (b) to study the waste generation rate, and (c) to determine the relationship between the quantity of waste generated and the factors like number of patients and beds in Lamjung District Community Hospital.

\section{MATERIALS AND METHODS}

\subsection{Ethics statement}

Prior to commencement of this study, permission to conduct the study was obtained from the Lamjung District Community Hospital. All participants gave oral consent in interview for this study. Respondents, who denied participating in interviews and questionnaire survey and seriously ill patients were excluded from this study.

\subsection{Background information about hospital}

Besisahar is a municipality and headquarter of Lamjung district in Gandaki province, Nepal. There is one community hospital and few small private hospitals and clinics. Lamjung District Community Hospital (LDCH) has been running under the management of Human Development Community Services (HDCS) with the support of the Government of Nepal. It has now 60 beds as well as a range of various services including staff quarters and cafeteria. It has currently 10 doctors, 20 nurses, 7 administrative staffs, 2 technicians, 8 security guards, 9 cleaners and 2 laborers. It provides patients with both diagnostic and curative services including 24-hours emergency care, laboratory testing, pharmacy service, radiology and ambulance services. A study from World Bank quoted that LDCH as being a model and largest hospital in Nepal. A large number of people including school students are exposed to the health-care waste. Therefore, it was selected to investigate the situation of health-care waste generation and the existing management scenario.

\subsection{Data collection}

Data were collected through field observations, interviews, and questionnaire survey during March-June 2019 AD. Simple Random Sampling Method was applied in this study. A structured questionnaire was used among 1041 (735 males and 306 females) respondents and the integrated questionnaire mainly focused on demographic profile of the participants, types and sources of hospital wastes, amount of wastes generated by the hospital, and methods for waste management practices. The responses were gathered by interview and through a questionnaire. Apart from the formal questionnaire survey, the informal discussions with patients, outpatients, visitors and hospital staffs were also conducted. The collected data for this study were analyzed to address the central issues of hospital waste management in relation to the generation of wastes from different sources. The data obtained by questionnaires were analyzed by simple descriptive statistics and the qualitative analysis of health care wastes was mainly taken as narrative in the present study. This method was considered for the qualitative abstraction of the understanding of present hospital waste management practices.

\section{RESULTS AND DISCUSSION}

\subsection{Level of awareness}

Biomedical waste handling is a sensitive process, which requires a high standard of preparation [2]. It requires a specific training that depends on the nature of the work in the hospital, the hazard and worker experience, and also the responsibilities of individual workers [3]. It was found that there is an insufficient awareness regarding to the magnitude of hospital waste management issue and inefficient communication among concerned individuals at different levels from directors through divisional heads to cleaners and laborers, patients and visitors. It was revealed that hospital is not performing a regular training and education for waste management to all hospital staffs, cleaners and laborers. Well structured training is required to raise an awareness level of health, safety and environmental issues $[18,8]$. It is important for workers to know and understand the potential risks associated with health-care waste $[19,20]$. The probability of getting infection is high in those who are not provided with special clothes like gowns, gloves and shoes respectively.

The results showed that $60 \%$ of the waste management workers are trained, whereas those of $40 \%$ are not. The $66.67 \%$ of the workers thought that safe disposal and segregation of the health-care waste need to be considered. The awareness of hospital waste management was studied between the ages of 15 to 85 including the hospital staffs, inpatients, outpatients and visitors respectively. The data indicated that around $79.167 \%$ of participants had a positive attitude, whereas $20.833 \%$ were unaware towards the safe management of health-care waste. In case of biomedical waste management, $86 \%$ of respondents agreed that biomedical waste causes health hazards. On average, $75.234 \%$ of participants consented that there must be regular educational programs on biomedical waste management.

Regarding biomedical waste disposal technique in the hospital, only $18.699 \%$ were aware; this shows that there is lack of strict protocol in the biomedical waste management. In addition, the knowledge regarding segregation of different wastes like plastic items, soiled dressing, impression material, extracted teeth, human tissue and plaster of paris in color-coded bags is inadequate. Based on questionnaires, negligible participants have knowledge regarding the government guidelines on waste management. There exists a lacuna in the knowledge and practice of biomedical waste management in LDCH. The positive attitude towards addressing this concern, workshops and trainings related to proper biomedical waste management could be a step forward towards attaining a healthy and safe environment for the future $[4,8,18]$. The hospital waste management awareness is given in Table 1.

Table 1: Hospital waste management awareness

\begin{tabular}{|c|c|c|c|c|c|c|}
\hline \multicolumn{4}{|c|}{ Hospital staffs } & \multicolumn{4}{c|}{ Inpatients and outpatients } \\
\hline Type & No. of respondents & Age range & Awareness (\%) & No. of respondents & Age range & Awareness (\%) \\
\hline Doctors & 8 & $25-45$ & 100 & 143 & $15-25$ & 65 \\
\hline Nurses and Auxiliary Nurse Midwives & 17 & $25-40$ & 90 & 180 & $25-35$ & 70 \\
\hline Administrative staffs & 7 & $30-45$ & 60 & 190 & $35-45$ & 80 \\
\hline Women cleaners, sweepers & 9 & $40-55$ & 50 & 220 & $45-55$ & 60 \\
\hline Technicians & 2 & $30-60$ & 65 & 115 & $55-65$ & 40 \\
\hline Security guards & 8 & $40-60$ & 45 & 90 & $65-75$ & 20 \\
\hline Laborers & 2 & $25-40$ & 65 & 50 & $75-85$ & 8 \\
\hline
\end{tabular}

\subsection{Waste handling}

The management of health-care waste is a major challenges for various hospitals and medical institutions in Nepal. Lack of proper knowledge and appropriate technique of handling of biomedical waste can lead to serious consequences on health and environment $[3,8,18]$. Eleven persons are 
responsible to work for hospital waste management in the LDCH. The workers do not have special training about infectious disease arising from biomedical waste. In survey, majority of waste collectors opted for this job to fulfill their basic needs as there is a very few employment options available to select for. The study found that majority (98\%) of workers are agreed to wear gloves and mask, while handling biomedical waste. It was observed that there is a poor segregation of different type of health-care wastes.

Large operating facilities that generate medical waste usually employ a color coding system to distinguish different types of waste. It reduces the technical difficulties and makes it less likely that human error will result in mixing of disparate waste $[8,19]$. Color coding also provides a visual indication of the potential risk posed by the waste, while the containers are in the facility of waste origin and after they have been transported elsewhere $[1,14]$. It was also found that hazardous wastes were often mixed with general wastes, thereby alarming the risk of infection. In LDCH, five separate colored bins are placed to segregate the biodegradable and non-degradable waste. The studied showed that additional bins should be required for special wards. The different types of wastes collected in color coding waste bins are presented in Table 2. It was visualized that hazardous chemicals, radioactive waste, waste with high contents of heavy metals such as batteries, pressurized containers etc. were not well handle in the hospital. It can be suggested that the space within LDCH is limited and finding a suitable area for the establishment of a waste treatment and storage center is a big challenge.

Table 3: Waste generation rate by patients

\begin{tabular}{|c|c|c|c|c|c|c|c|c|c|}
\hline \multirow{2}{*}{$\begin{array}{l}\text { Average no. of } \\
\text { outpatients }\end{array}$} & \multirow{2}{*}{$\begin{array}{l}\mathrm{kg} / \text { outpatient/ } \\
\text { day }\end{array}$} & \multirow{2}{*}{$\begin{array}{l}\text { No. of } \\
\text { beds }\end{array}$} & \multirow{2}{*}{$\begin{array}{l}\text { Average no. } \\
\text { of inpatients }\end{array}$} & \multirow{2}{*}{$\begin{array}{l}\text { Bed occupancy } \\
(\%)\end{array}$} & \multirow{2}{*}{$\begin{array}{l}\mathrm{kg} / \mathrm{bed} \\
\text { /day }\end{array}$} & \multirow{2}{*}{$\begin{array}{l}\text { kg/patient } \\
\text { /day }\end{array}$} & \multicolumn{2}{|c|}{ Average waste in kg/day } & \multirow{2}{*}{$\begin{array}{l}\text { Total } \\
\text { (kg/day) }\end{array}$} \\
\hline & & & & & & & Non-hazardous & Hazardous & \\
\hline 250 & 0.053 & 60 & 36 & 60 & 0.860 & 0.226 & 61.28 & 3.57 & 64.85 \\
\hline
\end{tabular}

\subsection{Waste types and generation rate}

The amount of waste generated in hospitals depends upon various factors such as the number of beds, types of health services provided, economic, social and cultural status of the patients and the general condition of the area, where the hospital is situated [18]. Improper segregation and disposal of hospital waste and mixing it with municipal waste can result in possible hazardous exposure to the health-care workers, waste handlers
Table 2: Color coding for collection of hospital wastes

\begin{tabular}{|l|l|}
\hline Type & Waste material \\
\hline Red & Plastic items, rubbers, gloves, infectious i.v. sets etc. \\
\hline Yellow & $\begin{array}{l}\text { Infectious dressing materials, pathological waste, human } \\
\text { organs, body parts, blood bags etc. }\end{array}$ \\
\hline Blue & Glass bottles, glass ampoules, infectious vitals etc. \\
\hline Green & Papers, paper cups, tissue paper, kitchen waste etc. \\
\hline Black & Expiry medicines, radioactive waste, cytotoxic waste etc. \\
\hline
\end{tabular}

\subsection{Waste generation by patients}

Recently, as the generation of health-care waste has increased; management of medical waste continues to be a major challenge [3] General and biomedical waste generation could be directly proportional to the number of beds available in the hospitals and medical institutions [1]. During our field survey, it was observed that the patients are responsible to generate the wastes like paper, textiles stained with blood, cotton pads, glass and plastic bottles, cans, foods, fruits and vegetables etc. including pathological and infectious wastes. It was further observed that outpatients are less responsible for waste generation comparison to inpatients. The waste generation rate was estimated around 36.542 and $9.383 \%$ by inpatient and outpatient respectively. In addition, total contribution of waste generated by patients per day was found at $43.397 \%$ of non-hazardous and $2.506 \%$ of hazardous waste respectively. The physical analyses of different wastes generated by patients are presented in Table 3.

Table 4: Physical analysis of hospital wastes

\begin{tabular}{|l|l|l|}
\hline Materials & Waste status & Weight in kg/day \\
\hline Textile and cottons & Non-hazardous & 3.00 \\
\hline Plastic and rubber gloves & Non-hazardous & 2.50 \\
\hline Paper and cardboard & Non-hazardous & 4.00 \\
\hline Broken bottles and glasses & Hazardous & 2.00 \\
\hline Waste from fracture clinics like plaster, bandages etc & Non-hazardous & 5.50 \\
\hline Syringe-needles and surgical blades & Hazardous & 0.50 \\
\hline Anatomical waste, materials contaminated with blood and body fluids & Hazardous & 4.00 \\
\hline Metals and cans & Non-hazardous & 1.50 \\
\hline Food, fruits and vegetables & Non-hazardous & 8.00 \\
\hline Pharmaceuticals waste & Non-hazardous & 1.50 \\
\hline Pathological waste & Hazardous & 1.00 \\
\hline Cytotoxic medicines & Hazardous & 0.045 \\
\hline Hazardous chemicals & Hazardous & 0.62 \\
\hline Other medicines & Non-hazardous & 1.50 \\
\hline Radioactive waste & Hazardous & 0.25 \\
\hline Waste from hospital canteen & Non-hazardous & 25.00 \\
\hline Waste from staff quarters & Non-hazardous & 16.00 \\
\hline Total & Non-hazardous & 69.058 \\
\hline Total & Hazardous & 7.857 \\
\hline Total (Including patients) & Non-hazardous & 130.338 \\
\hline Total (Including patients) & Hazardous & 11.427 \\
\hline Grand Total & & 141.765 \\
\hline
\end{tabular}


Hazardous wastes may cause cuts and injuries to the workers [4,19]. Table 4 shows the generation rate of the classes of waste. Generally, solid wastes, saline bags and non-sharps are disposed off in improper ways in LDCH. During our field survey, it was noted that some waste items such as plastics, empty packets, papers, rubbers, junk foods, skin of fruits, bottles, kitchen wastes and used X-ray film were found in open fields and pavements within the hospital premises. The survey showed that hospital has been still using mercury thermometer. It was observed that the total waste generated in hospital an average of $141.765 \mathrm{~kg} /$ day including waste generated by the patients. The contribution of non-hazardous and hazardous waste was estimated at 130.338 and $11.427 \mathrm{~kg} /$ day respectively. The percentage by weight of health-care waste components is presented in Figure 1. The questionnaire surveyed revealed that apart from separating syringes/needles, hospitals do not well practice waste segregation before disposal.

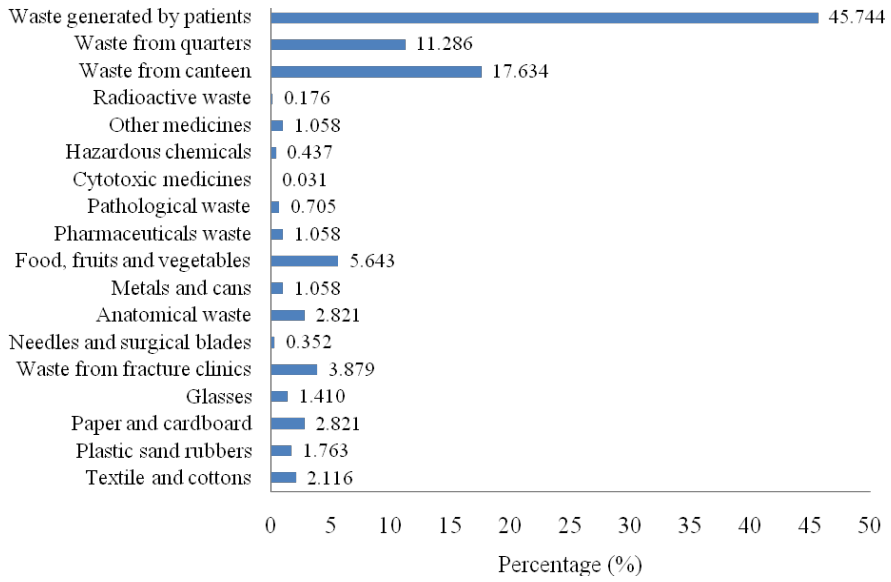

Figure 1: Percentage by weight of hospital waste components

\subsection{Waste disposal methods}

Waste can be managed either by reduction, reuse, recycle or recovery but all these waste management practices need new innovative technology. Waste management is not only limited to the health care institutions, but also challenging to the policy makers $[8,18]$. In LDCH, the biomedical wastes generated by the hospital are well segregated before their disposal. After segregation, the general waste is diverted to in municipality collection centre. The municipal dumping site is located in Marshyangdi riverbank. As the waste is dumped so close to the riverbank, there is a risk that the infectious waste gets mixed into the river when the water level rises, hence spreading infectious agents in the river stream [19,22]. It was also observed that the organic part of the waste was mixed with surface water and flew down to river.

The facilities available for the waste disposal in different hospitals included burial, burning and incineration [4]. The treatment and disposal process burn, and non-burn technology has been adopted in LDCH. Data showed that the combustible waste is burnt in open fields in order to dispose them. Due to contact with smokes from burning of solid wastes, gases emission from open fields burning may cause several diseases and even leads to a fatal diseases [14]. LDCH use own incinerator to dispose infectious, pathological and anatomical wastes. Biomedical waste is generally treated by incineration technology and the incinerated ash is disposed off in municipality landfill site. Hazardous waste containers or biodegradable bags are directly fed into the incinerator. There could be toxic air pollutants like dioxin, furans, mercury and lead released into environment by this method, which is risky to patients, hospital staff and people living around the hospitals [14,19]. Therefore, an alternative method should imply instead of incinerators due to environmental concern. Furthermore, autoclave used for only limited quantities of waste and for the highly infectious waste such as microbial cultures or sharps. It was seemed that an autoclave can be the best option to treat the medical waste to reduce the size of waste that has to go to the landfill sites $[16,17]$. It was further noticed that hospital does not have the bio-gas plant and wastewater treatment plant, which are necessary to generate the energy from the waste and to protect the environment.

\subsection{Economic analysis of health-care waste management}

Proper management of hazardous health-care waste is dependent with economic sustainability of the medical institutions. In most hospitals, choice of managing waste depends on the economic well being and the amount of expenditure over the waste management technology. The economic investment over managing waste governs the waste management policies and governmental intervention in the organizations. The biodegradable waste can be used for production of organic fertilizer and possible use in generation of bio-gas, which can reduce the overall cost of waste management. A major component of biogas is methane, which can be stored and distributed for the purpose of cooking, street lights and fuels used in small machines within the hospital. The treatment and utilization of health-care waste are much more expensive than general nonhazardous waste.

Table 5 shows the overall waste management costs in 2018 at LDCH. In $\mathrm{LDCH}$, the total investment in waste management including salaries of waste management workers was NPR 29,85,075 (\$US 26538.717). In addition, the value of hazardous waste treatment cost using autoclave, incinerator etc., especially, electrical charge was found around NPR 24,000 (\$US 213.371) for biomedical waste. The hospital should sale off recyclable wastes in order to overcome the waste management costs. On average, the yearly revenue generated from the selling off recyclable waste like papers, metals, plastic bottles, glasses etc. is around NPR 14,400 (\$US 128.022). The cost of health-care waste was found around NPR 57.917 (\$US 0.514) in $\mathrm{kg} /$ year. The disposed off health-care waste in a regular municipal waste landfill is an easy and low-cost waste disposal method, however it can raise human health risk and environmental pollution $[1,14]$.

Table 5: Overall waste management costs in 2018

\begin{tabular}{|l|l|l|}
\hline Particular & $\begin{array}{l}\text { Cost with VAT } \\
\text { (NPR/year) }\end{array}$ & $\begin{array}{l}\text { Cost in US } \\
\text { dollar }\end{array}$ \\
\hline Purchasing of bins, bags and tool & $2,25,475$ & 2004.578 \\
\hline $\begin{array}{l}\text { Items for waste management workers } \\
\text { special dresses, gloves, eye glasses, } \\
\text { capes and shoes etc. }\end{array}$ & 30,000 & 266.714 \\
\hline $\begin{array}{l}\text { Operating and management like } \\
\text { microwaves, incarcerator, autoclaves } \\
\text { etc (Specially electrical costs) }\end{array}$ & 24,000 & 213.371 \\
\hline $\begin{array}{l}\text { Charge for municipal waste } \\
\text { management }\end{array}$ & 30,000 & 266.714 \\
\hline $\begin{array}{l}\text { Salaries including OT for waste } \\
\text { management workers }\end{array}$ & $26,40,000$ & 23470.839 \\
\hline $\begin{array}{l}\text { Seminars for waste management } \\
\text { awareness programs }\end{array}$ & 50,000 & 444.523 \\
\hline $\begin{array}{l}\text { Income from recycling items like } \\
\text { metals, saline bottles, papers etc. }\end{array}$ & 14,400 & 128.022 \\
\hline $\begin{array}{l}\text { Note: Exchange rate of 24th August 2019 (1 US dollar=112.48 Nepali } \\
\text { rupees) }\end{array}$ & \\
\hline
\end{tabular}
rupees)

\subsection{Proposed health-care waste management scheme}

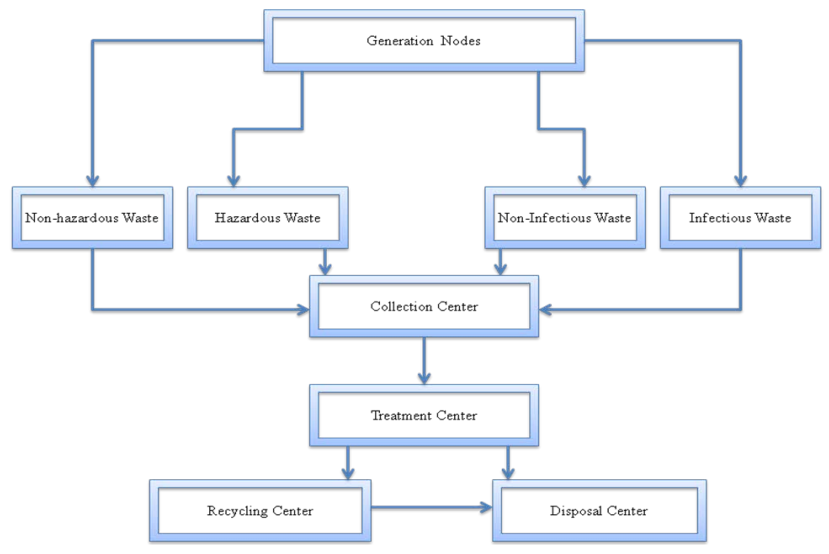

Figure 2: Conceptual framework for waste management in LDCH 
The harmful wastes produced from hospitals and other sectors should be transported and treated specifically in order to reduce their detrimental negative effect on human health and environment. The different treatment technologies such as incineration, chemical, biological and immobilization can be applied for hazardous waste. The proposed framework for management of LDCH waste is shown in Figure 2. Wastes are generally divided into non-hazardous, hazardous, infectious and non-infectious groups. Recycling and disposing are the important stages in hazardous waste management process. The recycling of waste is very important, since natural resources are going to deplete day by day. Hazardous and infectious waste can be treated with incineration technology. The segregated general health-care waste can be transported to the disposal centers.

\section{CONCLUSIONS}

A number of problems were identified with respect to solid waste management. The management of health-care waste is a major challenge in Lamjung District Community Hospital, Nepal. The data revealed that lack of awareness, inappropriate policy and laws, and unwillingness of stakeholders are responsible for the improper management of solid wastes. Due to the toxic nature of medical waste, improper handling may lead to the destruction of natural environment and disturb the balance of ecosystems. From the results of this study, it is obvious that medical waste management process is not practiced according to the recommended standards. There is the need for proper segregation of infectious medical waste and non-infectious medical waste. In the light of the above observations made during the research, environmental health experts and waste management experts must be included in the waste management team in the hospital. In addition, hospital should develop clear plans and policies for proper management and disposal off medical waste. It can be concluded that hospital waste management cannot be achieved successfully without the effective awareness program, knowledge, motivation, education and cooperation from the society.

\section{FUTURE RECOMMENDATIONS}

In the light of the results obtained from data surveyed, a number of recommendations are made for improving the solid waste management practice in Lamjung District Community Hospital. The following recommendations could enhance the hospital waste management:

1. It is important to segregate the infectious medical and non-infectious health-care waste periodically.

2. Hospital should develop awareness program related to the public health, safety and environmental issues as well as clear-cut plans and policies for proper waste management and disposal off infectious and hazardous waste.

3. Hospital must set up bio-gas and waste water treatment plant.

4. Hospital should get in touch with authorized manufactures for recycling of materials.

5. Hospital should search for efficient and environment friendly technologies for treatment of biomedical and hazardous waste.

\section{REFERENCES}

[1] Eleyan, D., Issam Al-Khatib, A., Garfield, J. 2013. System dynamics model for hospital waste characterization and generation in developing countries.

Waste Management \& Research, 31 (10). DOI:
10.1177/0734242X13490981.

[2] Gao, Q., Shi, Y., Mo, D., Nie, J., Yang, M., Rozelle, S. 2018. Medical waste management in three areas of rural China. PLoS ONE, 13 (7), e0200889. https://doi.org/10.1371/journal. pone.0200889.
[3] Sutha, I.A. 2018. An analytical study on medical waste management in selected hospitals located in Chennai city. Journal of Environmental Waste Management and Recycling, 1 (1), 5-8.

[4] Almuneef, M., Memish, Z.A. 2003. Effective medical waste management: it can be done. American Journal of Infection Control, 31 (3), 188-192.

[5] Hassan, M.M., Ahmed, S.A., Rahman, K.A., Biswas, T.K. 2008. Pattern of medical waste management: existing scenario in Dhaka City, Bangladesh. BMC Public Health, 8, 36.

[6] Prüss, A., Giroult, E., Rushbrook, D. 1999. Safe Management of Wastes from Health-care Activities World Health Organization: Geneva.

[7] Askarian, M., Vakili, M., Kabir, G. 2004. Results of a hospital waste survey in private hospitals in Fars province, Iran Waste, 24, 347-352.

[8] Tanuja, S., Tika, R.G., Santosh, K.A. 2018. Awareness of biomedical waste management in dental students in different dental colleges in Nepal. BioMed Res. Int., ID 1742326, https://doi.org/10.1155/2018/1742326.

[9] Abor, P.A., Bouwer, A. 2008. Medical waste management practices in a Southern African hospital. Int. J. Health Care Qual Assur., 21, 356-364.

[10] Joshi, S.C., Diwan, V., Tamhankar, A.J., Joshi, R., Shah, H., Sharma, M. 2015. Staff perception on biomedical or health care waste management: A qualitative study in a rural tertiary care hospital in India. PLoS ONE, 10 (5), e0128383. doi:10.1371/journal.pone.0128383

[11] Klangsin, P., Harding, A. 1998. Medical waste treatment and disposal methods used by hospitals in Oregon, Washington andIdaho. Journal of the Air \& Waste Management Association, 48, 516-526.

[12] Levendis, Y., Atal, A., Carlson, J., Quintana, M. 2001. PAH and soot emissions from burning components of medical waste: examination/surgical gloves and cotton pads. Chemosphere, 42, 775-783.

[13] Silva, C.E., Hoppe, A.E., Ravanello, M.M., Mello, N. 2005. Medical waste management in the south of Brazil. Waste Management, 25, 600-605.

[14] Maryam, K.G., Rosnah, B.M.Y. 2016. Advantages and disadvantages of healthcare waste treatment and disposal alternatives: Malaysian scenario. Polish Journal of Environmental Studies, 25, 17-25.

[15] Ananth, A.P., Prashanthini, V., Visvanathan, C. 2010. Healthcare waste management in Asia. Waste Management, 30 (1), 154-161.

[16] Katoch, S.S. 2008. Investigations on common treatment technologies for some biomedical wastes. Department of Chemical Engineering Thapar, University of India. India.

[17] Liu, H.C., Wu, J., Li, P. 2013. Assessment of health-care waste disposal methods using a VIKOR-based fuzzy multi-criteria decision-making method. Waste Management, 33 (12), 2744-2751.

[18] Amin, R., Gul, R., Mehrab, A. 2013. Hospital waste management; practices in different hospitals of Distt. Peshawar. The Professional Medical Journal, 20 (6), 988-994.

[19] Joshi, H.D. 2013. Health-care waste management practice in Nepal. Journal of Nepal Health Research Council, 11 (23), 102-108.

[20] Jasem, M., Alhumoud, H., Alhumoud, M. 2007. An analysis of trends related to hospital solid wastes management in Kuwait. Journal of Environmental Management, 18, 502-513.

[21] Blenkharn, J.I. 2006. Standards of clinical waste management in UK hospitals. Journal of Hospital Infection, 62 (3), 300-303.

[22] Patil, A.D., Shekdarf, A.V. 2001. Health-care waste management in India. Journal of Environmental Management, 63, 211-20. 